\title{
Bitlis ilinde acil servise üst gastrointestinal kanama ile başvuran hastaların endoskopik ve demografik verilerinin değerlendirilmesi
}

Endoscopic and demographic features of patients presenting to the emergency department with upper gastrointestinal bleeding in Bitlis province

Ramazan GÜVEN ${ }^{1}$, Gökhan EYÜPOĞLU', Ufuk Barış KUZU²

Bitlis Devlet Hastanesi, ${ }^{1}$ Acil Servis Kliniği, ${ }^{2}$ Gastroenteroloji Kliniği, Bitlis

Giriş ve Amaç: Üst gastrointestinal sistem kanamaları acil servise başvuruların önemli bir nedeni olup, erken tanı ve tedavi gerektirmektedir. $\mathrm{Bu}$ çalışmanın amacı Bitlis ilinde üst gastrointestinal sistem kanaması tanıs alan hastaların özelliklerini değerlendirmektir. Gereç ve Yöntem: Ocak 2014-Aralık 2017 tarihleri arasında Bitlis Devlet Hastanesi acil servisi kliniğine üst gastrointestinal sistem kanaması nedeni ile başvuran hastaların verileri retrospektif olarak incelendi. Bu hastaların klinik özellikleri ve kanamaya yo açabilecek etiyolojik nedenler değerlendirildi. Bulgular: Çalışmaya toplam 54 hasta alındı. Hastaların çoğunluğunu erkekler (\%59.3) oluşturmaktaydi. En sik başvuru șikayeti hematemezdi. Hastaların \%22.8'inde kanamaya predispozan olabilecek ilaç kullanımı mevcuttu. Hastaların ortalama yatıs süresi 5.6×3.6 gün idi. Etiyolojik açıdan en sık neden duedonum ve mide ülseri olarak saptandı. Sonuç: Bitlis ilinde üst gastrointestinal sistem kanamas olan hastaların genel özellikleri ülkemizde bu konu ile ilgili yapılan diğer çalışmalar ile uyum göstermekteydi.

Anahtar kelimeler: Gastrointestinal kanama, endoskopi

\section{GİRISs}

Üst gastrointestinal kanama (ÜGK), treitz ligamentinin proksimalinden kaynaklanan ve potansiyel olarak yaşamı tehdit eden bir durumdur. Insidansı, 100.000 nüfusta 50 ile 172 birey arasındadır. Son yıllarda endoskopik ve radyolojik yöntemlerdeki önemli gelişmelere rağmen, mortalite oranı \%2-15 ve tekrar kanama oranı \% 10-20 arasında bildirilmiştir (1-3).

Acil servise başvuran hastaların yaklaşık \% l'ini ÜGK şüphesi olan olgular oluşturmaktadır (4). ÜGK'nın acil servisteki yaklaşım ve yönetimi temel olarak klinik değerlendirmeye bağlıdır. Bu hastalarda klinik durum normal fizik muayene bulgularından hipovolemik şok tablosuna kadar geniş bir yelpazede seyredebilir. Bu yüzden intravasküler hacim resüsitasyonu ile hemodinaminin sağlanması ve korunması ilk etapta hayat kurtarıcıdır (2).

ÜGK ile başvuran hastalarda endoskopi tanıda majör rolü oynamakta ve eş zamanlı tedavi imkanı da sunmaktadır. Endoskopik değerlendirmelerde birçok hastalığın ÜGK'ya neden olabileceği gösterilmekle beraber günümüzde olguların yaklaşık yarısında peptik ülsere bağlı kanama saptanmaktadır $(5,6)$.

Güven R, Eyüpoğlu G, Kuzu UB, Endoscopic and demographic features of patients presenting to the emergency department with upper gastrointestinal bleeding in Bitlis province. Endoscopy Gastrointestinal 2018;26:54-56.
Background and Aims: Upper gastrointestinal tract hemorrhage is an important cause of urgent hospital admissions and requires early diagnosis and treatment. The aim of this study was to evaluate the clinical features of patients diagnosed with upper gastrointestinal tract hemorrhage in Bitlis. Materials and Methods: Patients attending the emergency department of Bitlis State Hospital for symptoms of upper gastrointestinal bleeding between January 2014 and December 2017 were evaluated retrospectively. The clinical characteristics of these patients and the etiologic causes that could lead to bleeding were evaluated. Results: Fifty-four patients were included in the study, and most of them were male (59.3\%). The most common presenting symptom was hematemesis. In all, $22.8 \%$ of patients had a history of using medications that could predispose them to a higher risk of bleeding. The

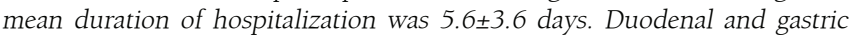
ulcers were the most common etiologic factors. Conclusion: The general characteristics of the patients diagnosed with upper gastrointestinal tract hemorrhage in Bitlis were compatible with related studies in our country.

Key words: Gastrointestinal bleeding, endoscopy

Çalışmamızda, acil servise ÜGK nedeni ile başvuran hastaların, demografik özelikleri ve endoskopi bulguları eşliğinde klinik sonuçların değerlendirilmesi amaçlandı.

\section{GEREÇ ve YÖNTEM}

Çalışma Ocak 2014-Aralık 2017 tarihleri arasında Bitlis Devlet Hastanesi acil servisi kliniğine ÜGK nedeni ile başvuran hastaların verileri retrospektif olarak değerlendirildi. Değerlendirilmeye alınan hastalar, "SISOFT" hastane işletim sistemi içerisinden gastrointestinal kanama için kullanılan ICD kodları girilerek belirlendi. Çalışmaya dahil edilen hastaların acil servis triaj formları ve dosyaları taranarak veriler elde edildi. Dosya bilgileri yetersiz olan ve üst gastrointestinal sistem endoskopisi yapılmayan hastalar çalışmadan dışlandı.

\section{Çalışma Verileri}

Her bir hasta için verileri içeren standart bir form oluşturuldu. Bu form aşağıdaki bilgileri içeriyordu: 1-Demografik özellikler. 2- Hastalık özgeçmişi ve kullanılan ilaçlar. 3- Başvuru şikayeti (hematemez, melena, hematokezya, senkop, 
halsizlik-baş dönmesi). 4- Endoskopi bulguları (mide ülseri, duedenal ülser, eroziv gastrit, bulbit, eroziv özafajit, mide tümörü, özofagus varis kanaması, dieulafoy lezyonu, mide polibi vs...). 5- Endoskopik tedavi tipi (skleroterapi, argon plazma koagülasyon, elektrokoagülasyon, band ligasyonu). 6- Laboratuvar verileri. 7- Kanama tekrarının varlığı. 8-Hastanın yatıss süresi ve klinik sonuç.

\section{İstatistik}

Verilerin istatistiksel analizi Statistical Package for Social Sciences (SPSS) version 18 (SPSS Inc., Chicago, IL, United States) bilgisayar program kullanılarak yapıldı. Sürekli değerler alan veriler ortalama ( \pm standart sapma), gerektiğinde ortanca değer (Çeyrekler arası aralık; 25.-75. persentiller) olarak, kategorik veriler sıklık ve yüzde olarak (n, \%) sunulmuştur.

\section{BULGULAR}

Çalışmada toplam 66 hastanın verileri analiz edildi. On iki hasta yetersiz veri nedeni ile çalışma dışı birakıldı. Geriye kalan 54 hastanın yaş ortalaması $50.59 \pm 17.9$ yll (18-97) idi. Olguların çoğunluğunu erkek cinsiyet (\%59.3, n=32) oluşturmaktaydı. Hastaların acil servise en sık başvuru şikayetleri hematemez ve melenaydı. Hastaların başvuru anında ortalama hemoglobin değeri $9.95 \pm 2.89 \mathrm{mg} / \mathrm{dl}$ idi. Hastaların \%66.6'sında ( $n=42)$ yakın zamanda ilaç kullanım öyküsü bulunmazken, en sık kullanılan ilaçlar sırası ile \%11.1 ( $\mathrm{n}=6)$ asetil salisilik asit (ASA), \%5.6 (n=3) non-steroid antiinflamatuvar ilaç (NSAII) ve \%5.6 (n=3) warfarin oluşturmaktaydı (Tablo 1).

Endoskopik değerlendirme sonucuna göre en sik saptanan lezyon duedenal ülser $(n=17, \% 31.5)$ ve mide ülseriydi $(\mathrm{n}=14, \% 25.9)$. Bunları sirası ile eroziv gastrit $(\mathrm{n}=4, \% 7.4)$, malignite ( $n=4, \% 7.4)$, özofagus varis kanaması ( $n=3, \% 5.6)$, özofagus ülseri/özofajit ( $\mathrm{n}=2, \% 3.7)$, anastomoz ülseri ( $\mathrm{n}=2$, \%3.7) ve kameron ülseri ( $\mathrm{n}=1, \% 1.9)$ izliyordu. Hastaların \%12.9'unda ( $\mathrm{n}=7)$ endoskopik değerlendirmede kanamaya neden olabilecek lezyon saptanmadı (Tablo 2).

Endoskopi sırasında terapötik işlem gereksinimi olan hasta sayısı 15 (\%27.7) idi. Terapötik işlem yapılan bu hastaları büyük çoğunluğunu mide ve duedenal ülserli hastalar oluşturmaktaydı. Terapötik işlemlerin \%60'ını (n=9) adrenalin ile uygulanan skleroterapi, \%20'sini (n=3) skleroterapi+bipolar koagülasyon, \%13.3'ünü ( $\mathrm{n}=2$ ) band ligasyonu ve \%6.6'sinı $(\mathrm{n}=1)$ argon plazma koagülasyon oluşturuyordu.

Hastaların ortalama yatış süresi 5.6×3.6 gün idi. Toplam 2 hastada mortalite izlendi. Ilk hastanın ko-morbit hastalıkları mevcuttu ve endoskopisinde duedenal ülser saptandı. Diğer hastada ise Child-C karaciğer sirozu mevcuttu. Beş hastada takip sırasında tekrar kanama izlendi. Tekrar kanayan has-
Tablo 1. Hastaların genel özellikleri ve klinik bulguları

$\begin{array}{ll}\text { Yaş (yıl) } & 59.59 \pm 17.9 \\ \text { Cinsiyet (Erkek/Kadın) } & 32 / 22 \\ \text { Başvuru şikayeti (n, \%) } & \\ \text { Hematemez } & 25(46.3) \\ \text { Melena } & 16(29.6) \\ \text { Halsizlik/Baş dönmesi } & 12(28.2) \\ \text { Hematokezya } & 2(3.7) \\ \text { Senkop } & 3(5.5) \\ \text { Ilaç öyküsü (n, \%) } & \\ \text { Yok } & 36(66.6) \\ \text { Asetil salisilik asit } & 6(11.1) \\ \text { Nonsteroid anti-inflamatuvar ilaç } & 3(5.6) \\ \text { Warfarin } & 3(5.6) \\ \text { Klopidogrel } & 2(3.7) \\ \text { Çoklu ilaç } & 4(7.4) \\ \text { Yatış süresi (gün) } & 5.6 \pm 3.6\end{array}$

\section{Tablo 2. Hastaların endoskopik değerlendirmesine} göre en sık kanama nedenleri

\begin{tabular}{|l|l|}
\hline Lezyon & Oran (n, \%) \\
\hline Duedenal ülser & $17(31.5)$ \\
\hline Mide ülseri & $14(25.9)$ \\
\hline Eroziv gastrit & $4(7.4)$ \\
\hline Malignite & $4(7.4)$ \\
\hline Özofagus varis kanaması & $3(5.6)$ \\
\hline Özofagus ülseri/özofajit & $2(3.7)$ \\
\hline Anastomoz ülseri & $2(3.7)$ \\
\hline Kameron ülseri & $1(1.9)$ \\
\hline Lezyon yok & $7(12.9)$ \\
\hline
\end{tabular}

taların hepsine ikinci kez endoskopik işlem gerçekleştirildi. Tekrar kanaması olan hastaların 2'sinde mide ülseri, 2'sinde duedenal ülser ve bir hastada mide kanseri mevcuttu. Bu hastaların hepsine tekrar terapötik endoskopi yapıldı. Ülseri olan 4 hastanın takiplerinde tekrar kanama olmazken, mide kanseri olan hasta anjiografik girişim amaçlı üçüncü basamak merkeze sevk edildi.

\section{TARTISMA}

Ciddi mortalite oranı nedeni ile ÜGK, gerek acil servisteki yönetimi gerekse endoskopik olarak yaklaşımı önemli yer tutmaktadır. Bitlis yöresinde ÜGK nedeni ile başvuran hastalar değerlendirildiğinde, hastaların büyük kısmını erkek cinsiyet ve yaşlı hasta grubu oluşturmaktaydı. Literatüre bakıldığında 
ÜGK ortalama olarak 60 yaş civarında görülmekte olup, erkeklerde yaklaşık 2 kat daha sık görülmektedir. Ülkemizde farklı bölgelerinde ve yurt dışında yapılan çalışmalarda benzer sonuçlara ulaşıldığı görülmektedir (7-9).

Yapılan çalışmalarda ÜGK'nın en sık nedenleri olarak duedenal ve gastrik ülser olduğu görülmektedir. Yöremizde de literatürü destekleyecek şekilde bu 2 hastalığın en sık nedenler olduğu izlenmiştir. Ülkemizde, Trabzon'da Türedi ve arkadaşlarının yaptığı çalışmada, çalışmamızda olduğu gibi en sık nedenler duedenal ülser, mide ülseri ve eroziv gastrit olarak saptanmıştır. Antalya'da yapılan başka bir çalışmada da benzer sonuçlara ulaşılmıştır $(7,10)$. Çalışmamızda ÜGK nedeni olarak malignitesi olan hastaların oranı \%7.4 olarak saptandı. Ülkemizde farklı coğrafi bölgelerde yapılan çalışmalarda bu oran \%3.4-9.5 arasında saptanmıştır. ÜGK'nın genel nedenlerinden biri olan özofagus varis kanamasının oranı ise \%5.6 olarak bulunmuş olup, ülkemizdeki sıklığı ise \%12.3-19 aralığında değişmektedir. Bizim oranımızın düşük olmasının nedeni muhtemel bu hastaların 3. basamak hastanelere sevki veya direkt olarak başvurmasından kaynaklanmaktadır $(6,7,10)$.

ÜGK için en önemli risk faktörlerden biri de ilaç kullanımı olup, en sik nedenleri ASA, non-steroid anti-inflamatuvar ilaçlar (NSAit) ve antikoagülan ilaçlar oluşturmaktadır. Çalışmamızda hastaların yaklaşık dörtte birinin ilaç kullanımı mevcut olup en sık kullanılan ilaçlar literatür ile uyumlu

\section{REFERANSLAR}

1. Longstreth GF. Epidemiology of hospitalization for acute upper gastrointestinal hemorrhage: a population-based study. Am J Gastroenterol 1995;90:206-10.

2. Silverstein FE, Feld AD, Gilbert DA. Upper gastrointestinal tract bleeding. Predisposing factors, diagnosis, and therapy. Arch Intern Med 1981;141:322-7.

3. Köksal Ö, Özeren G, Özdemir F, et al. Prospective validation of the Glasgow Blatchford scoring system in patients with upper gastrointestinal bleeding in the emergency department. Turk J Gastroenterol 2012;23:448-55.

4. Paspatis GA, Matrella E, Kapsoritakis A, et al. An epidemiological study of acute upper gastrointestinal bleeding in Crete, Greece. Eur J Gastroenterol Hepatol 2000;12:1215-20.

5. Del Piano M, Bianco MA, Cipolletta L, et al; Prometeo study group of the Italian Society of Digestive Endoscopy (SIED). The "Prometeo" study: online collection of clinical data and outcome of Italian patients with acute nonvariceal upper gastrointestinal bleeding. J Clin Gastroenterol 2013;47:e33-e7.

6. Içme F, Satar S, Akın FE, et al. Analysis of endoscopic and demographic data of the patients admitted to the emergency department with non-variceal upper gastrointestinal bleeding. Turkish Medical Journal 2011;5:5-11.

7. Göksu E, Erken Ö, Erçetin Y, et al. Factors effecting mortality and demographic properties of patients presenting to the emergency department of Akdeniz University Hospital with upper gastrointestinal bleeding. Turk J Emerg Med 2004:4:121-6. olarak izlendi. Ancak bazı çalışmalarda ÜGK ile başvuran hastalarda ilaç kullanım oranı \%52-60 gibi oldukça yüksek değerlerde bildirilmiştir $(6,9)$. Yukarıda bahsedilen ilaçlar içerisinde özellikle NSAIl toplumda sıklıkla kullanılmaktadır. NSAII, peptik ülser riskini 5-6 kat artırmaktadır ve bu hastaların yaklaşı \% 1-4'ünde ülsere bağlı komplikasyon gelişmektedir $(11,12)$. Bu nedenle ÜGK için orta ve yüksek risk sınıf taşıyan hastalara ek olarak proton pompa inhibitörü verilmesi gerektiği unutulmamalıdır (13).

ÜGK, kan kaybı ve çoğu zaman eşlik eden ko-morbid hastalıklar nedenleri ile yaşlı hastalar tarafından daha az tolere edilmektedir. Bu nedenle özelikle ko-morbit hastalığı olan yaşlı hastalarda ÜGK olması durumunda destek tedavisi ile erken hemostazın sağlanması ve endoskopik girişim oldukça önem taşımaktadır. Çalışmamızda mortalite izlenen her iki hasta da yaşlı olup, ko-morbit hastalıklar eşlik ediyordu. Ülkemizde farklı bölgelerde yapılan çalışmalarda mortalite oranı \%1.49 arasında olup çalışmamıza benzer şekilde çoğu ko-morbit hastalığı olan yaşlı hastalardan oluşmaktaydı (6-8).

Sonuç olarak, ÜGK olan hastalar hayati riskleri nedeniyle hızlı yaklaşım gerektirip, dikkatle izlenilmesi gerekmektedir. Yöremizde ÜGK nedeni ile başvuran hastaların genel özellikleri ülkemizde bu konu ile ilgili yapılan diğer çalışmaların sonuçları ile uyumluluk göstermekteydi. Hastalarımızın çoğunluğunu erkek ve yaşlılar oluşturmaktaydı. Etiyolojik olarak en sık nedenler mide ve duedonum ülseri olarak izlendi.

8. Gündüz A, Kesen J, Topbaş M, et al. Acil servise başvuran üst gastrointestinal sistem kanamalı olguların retrospektif analizi. Iç Hastalıkları Dergisi 2004;11:57-61.

9. Theocharis GJ, Arvaniti V, Assimakopoulos SF, et al. Acute upper gastrointestinal bleeding in octogenarians: clinical outcome and factors related to mortality. World J Gastroenterol 2008;14:4047-53.

10. Türedi S, Gündüz A,Yandı M. An etiological and prognostic evaluation of patients with upper gastrointestinal bleeding from Karadeniz Technical University Department of Emergency Medicine. Turk J Emerg Med 2010;10:20-5.

11. Garcia Rodriguez LA, Hernandez-Diaz S. Relative risk of upper gastrointestinal complications among users of acetaminophen and nonsteroidal anti-inflammatory drugs. Epidemiology 2001;12:570-6.

12. American Gastroenterological Association, Wilcox CM, Allison J, Benzuly $\mathrm{K}$, et al. Consensus development conference on the use of nonsteroidal anti-inflammatory agents, including cyclooxygenase-2 enzyme inhibitors and aspirin. Clin Gastroenterol Hepatol 2006;4:1082-9.

13. Pearson TA, Blair SN, Daniels SR, et al. AHA Guidelines for Primary Prevention of Cardiovascular Disease and Stroke: 2002 Update: Consensus Panel Guide to Comprehensive Risk Reduction for Adult Patients Without Coronary or Other Atherosclerotic Vascular Diseases. American Heart Association Science Advisory and Coordinating Committee. Circulation 2002;106:388-91 